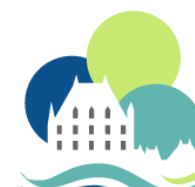

ISCAR 2017

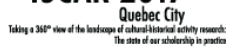

\title{
The Perception of Art as a Higher Mental Function
}

\author{
Dmitry V. Lubovsky \\ Department of Educational Psychology \\ Moscow State University of Psychology and Education \\ Moscow, Russia
}

\begin{abstract}
The concept of higher mental functions applied to the perception of artworks. Considering art as a system of means for mastering of emotions and feelings, the authorshows that this interpsychic system of means for mastering the feelings and emotions through the processing of aesthetic experience is a conscious, mediated by speech and arbitrary dynamic system of artistic images perception and the processing of aesthetic experience. Perception of artworks becomes arbitrary, if a person realizes the cultural norm of relation to the arts, representing the ability and desire of the viewer to see in the artwork of thoughts and feelings appropriate to the author.

The formation of art perception, like any other higher mental functions takes place in accordance with genetic law of cultural development according to which "Every function in the cultural development of the child appears on stage twice" (Vygotsky, 1983, p. 145). The author shows that the perception of art as a higher mental function is formed on the entire life through the perception of works of art and the assimilation of aesthetic experience.

The approach to the analysis of perception of works of art proposed by author can find application in different social practices, from art pedagogy to art therapy; it allows to select the period of development of this function in childhood and adolescence as requiring the greatest attention by teachers and parents. The approach is applicable also in a psychological counseling and art therapy for adolescents and adults.
\end{abstract}


The theoretical principles of L. S. Vygotsky's cultural-historical theory are being used ever wider. In particular, the notion of higher mental functions is used in areas where previously it was not used. Meanwhile, this concept, paradoxically, still is not used to the field of study where Vygotsky began to create cultural-historical theory on a material of the perception of artworks. "The central idea of the psychology of art, we believe the recognition of overcoming the material by art form or what is the same, the recognition of the art as a public technique of feelings" (Vygotsky, 1968, p. 12). In other terms, the art is a created by people and depicted in the culture as works of art and literature system of means for mastering of our emotions and feelings. But, obviously, the experience gained by the person from the perception of works of art cannot help her/him to process feelings and emotions, if the intrapsychic system of means for mastering the feelings and emotions wasn't formed through the processing of aesthetic experience.

The entire cultural-historical theory created by L. S. Vygotsky after his "Psychology of art", argues that this system of means for mastering the feelings and emotions is a higher mental function, i.e., conscious, mediated and arbitrary functional system for perception of artistic images and the processing of aesthetic experience. The awareness of aesthetic experiences is mediated by the word; this function is a system where the passion is inseparable from intellect in this structure and cognitive processes form a living system used by the viewer or reader for understanding of artworks. Perception of works of art becomes arbitrary, if it implements the cultural norm of the relation to arts, i.e. the ability and desire of the viewer to see the work of thoughts and feelings appropriate to the author's idea (Guruzhapov, 1999). An attempt to understand, the intent of the artist is a conscious effort, what makes the perception of artworks an arbitrary mental function.

The formation of art perception, like any other higher mental functions, takes place in accordance with genetic law of cultural development according to which "Every function in the cultural development of the child appears on stage twice, in two plans, - first social, then - psychological, first between people as an interpsychic category, then within the child as an intrapsychic category" (Vygotsky, 1983, p. 145). Like any other higher mental function, this kind of perception is formed over many years, in childhood and adolescence in the process of art education and throughout life, in the process of obtaining aesthetic experience.

The perception of works of art and the assimilation of obtained aesthetic experience develop this function throughout human life always when a person is drawn to art to resolve the problems of spiritual development. The formation of perception of artistic images as a higher mental function is one of the decisive conditions for acquaintance with the work of art became the encounter facilitating change itself. Any encounter with an artwork is initiating the experiencing as an internal activity, "by which a person is able to overcome certain (usually severe) life events and conditions, to restore the lost mental balance, in short, to cope with the critical situation" (Vasilyuk, 1984, p. 12), becomes a step in the development of mastering their emotions and feelings in case that the encounter as an event was completed and the resulting spiritual experiences are assimilated. But in order to meet the aesthetic experience took place, it is required that the person had, in addition 
to passions, a system of artistic perception means allowing to perceive the emotions and feelings inherent by the author in the work.

The approach to artworks perception analysis proposed in this article can find application in different social practices, from art pedagogy to art therapy. This approach allows selecting the period of development of this function in childhood and adolescence which requiring the greatest attention by teachers and parents. The approach is applicable also in a psychological counseling and art therapy for adolescents and adults.

\section{References}

Guruzhapov, V. A. (1999). How to teach children to understand art. essays on the psychology of the generation of the meaning of the paintings and drawings. Moscow: RIA "My i mir".

Vasilyuk, F. E. (1984). Psychology experiences. Analysis of overcoming critical situations. Moscow: Izd-vo Mosk. University Press.

Vygotsky, L. S. (1968). Psychology of art. 2nd edition. Moscow: Iskusstvo.

Vygotsky, L. S. (1983). Collected works in 6 volumes. Vol. 3. Problems of psychic development. Moscow: Pedagogika. 